\title{
Investment Policies to Extend the Life of Expressways in Japan
}

\author{
Hideo Noda ${ }^{1}$ and Yuichi Osano ${ }^{2}$ \\ ${ }^{1}$ Tokyo University of Science, Tokyo, Japan \\ ${ }^{2}$ Osaka School of International Public Policy, Osaka, Japan \\ Correspondence should be addressed to Hideo Noda; noda@rs.tus.ac.jp
}

Received 25 January 2017; Revised 18 May 2017; Accepted 4 June 2017; Published 18 July 2017

Academic Editor: Manuel De la Sen

Copyright (C) 2017 Hideo Noda and Yuichi Osano. This is an open access article distributed under the Creative Commons Attribution License, which permits unrestricted use, distribution, and reproduction in any medium, provided the original work is properly cited.

\begin{abstract}
This study examines the macroeconomic effects of investment policies aimed at extending the life of expressways in Japan based on a stochastic Ramsey model. The results of numerical analysis suggest that the benefits of life-extension investment in expressways can be increased by raising the level of maintenance intensity of expressways. The benefits of life-extension investment in expressways can be decomposed into the stock effect and the smoothing effect. Decomposition of life-extension benefits shows that the contribution of the stock effect is more than 90 percent, while that of the smoothing effect is less than 10 percent. The implementation of life-extension investment policies regarding expressways offers advantages in terms of reducing economic fluctuations and user charges. In addition, if relative risk aversion is high, efficiency is low and intergenerational equity is high. Furthermore, a higher level of technology leads to greater efficiency and intergenerational equity.
\end{abstract}

\section{Introduction}

Japan has one of the most highly developed multimodal transport systems in the world, made possible by the successful construction of an extensive expressway network [1]. Expressways constitute an essential logistics element in the Japanese economy and play a prominent role in influencing macroeconomic performance. However, aging expressway infrastructure has become a serious problem in recent years. With governments facing financial difficulties, the maintenance and renewal of expressway infrastructure are a significant issue. In this context, the purpose of this study is to evaluate investment policies to extend the life of expressways in Japan.

There are some earlier studies regarding the economic impact of maintenance and renewal of infrastructure in Japan. For example, [2] estimated the required renewal cost from 2013 to 2040 (fiscal years) and examined the effect of the suppression of new investment on the life expectancy of existing expressways. Based on the analytical results of [2], if we can decrease total infrastructure through city intensification, such as by building more compact cities, it will be possible to reduce future renewal costs without reducing living standards. Paper [3] analyzed the effect of investment policies aimed at extending the life of economywide infrastructure in Japan and found that the decrease in life-cycle costs resulting from life-extension investment increases the resources available for consumption and investment. Recent studies of the relationship between efficiency and intergenerational equity regarding road charging systems include that of [4]. Applying the generational accounting technique of [5], [4] concluded that management of roads based on a long-term social marginal cost pricing system has a favorable effect on intergenerational equity.

Note that [2] did not analyze intergenerational equity in terms of the cost burden. Paper [3] failed to find a clear relationship between efficiency and intergenerational equity associated with a life-extension investment policy on economy-wide infrastructure. Although [4] discussed the relationship between efficiency and intergenerational equity, [4] did not focus on a life-extension investment policy for expressways, but rather on road construction to optimize capacity. In addition, the model of [4] is essentially a static framework.

To our knowledge, there has been a lack of dynamic modeling approaches to investigating the macroeconomic 
effects of life-extension investment policies on various types of infrastructure. When we discuss a life-extension investment policy, it is not sufficient to only analyze the benefits of extending the life of the infrastructure. It is also important to consider the issues of total expenditure on infrastructure, user charges, efficiency, and intergenerational equity. However, previous studies have treated the above-mentioned issues separately and hence have failed to analyze the linkage with life-extension investment policies. Unlike earlier studies, we consider issues related to decomposing the benefits of life-extension investment policies for expressways, the dynamics of total expenditure on expressway infrastructure and user charges, and the relationship between efficiency and intergenerational equity. A key contribution of this study is the presentation of qualitative and quantitative effects of life-extension investment policies on expressways in Japan within the context of macroeconomic dynamics. There is no existing literature analyzing the macroeconomic effects of life-extension investment policies on expressways in Japan. Thus, this study is of particular interest to policy-makers and expressway-related companies, because Japan is now confronted with aging expressway infrastructure. Policy evaluation based on modeling of macroeconomic dynamics has been increasingly emphasized in recent years. Our dynamic modeling approach is useful as a tool for verification of policies and forecasting of effects. This is the methodological contribution of this study.

The role of infrastructure in macroeconomic performance has been studied in the context of various models of economic growth, beginning with [6]. Many conventional studies focused on the common issue: How does infrastructure investment influence economic growth and welfare? There are three types of models regarding the impact on growth and welfare performance of infrastructure development. The first type treats public expenditure as a flow [7-9]. The second type starts with the idea that as long as productive public expenditure is intended to develop infrastructure, it should be represented as stock, rather than as a flow [10-12]. The third type considers both the role of public expenditure as a flow and that of public capital as stock underpinning economic growth [13-15]. In conventional studies, however, the importance of maintenance has been less evident from the perspective of economic growth models. Since the 2000s, several attempts to develop economic growth models incorporating maintenance of infrastructure have been seen [16-19].

This study is also in line with [16-19] in emphasizing the role of maintenance in infrastructure development. We construct a stochastic Ramsey model for analyzing life-extension investment policies for expressways, mainly based on $[3,4]$. A notable feature of our model is that a technology parameter is incorporated into the model to enable a better understanding of the relationship between efficiency and intergenerational equity. In addition, we apply Markov vintage modeling for the accumulation of expressway stock. Thereby, we can analyze the complicated movement of total expenditure on expressways and user charges. In our numerical analysis, we focus on two cases illustrating the intensity of maintenance of expressways (the ratio of expenditure on expressway maintenance to the total amount of expressway stock) to analyze a life-extension policy. In the first case, the expressway stock reaches its serviceability limit after 50 years. In the other case, the expressway stock reaches its serviceability limit after 70 years.

The following main results are obtained. From the shortterm perspective, total expressway expenditure and user charges in the case with a serviceability limit of 70 years are larger than in the case with a serviceability limit of 50 years in some periods. However, from the long-term perspective, total expenditure on expressways and user charges in the case with a serviceability limit of 70 years are smaller than in the case with a serviceability limit of 50 years. That is, in the long term, we can certainly decrease total expenditure on expressways and user charges by increasing the maintenance intensity. Regarding the relationship between efficiency and intergenerational equity associated with life-extension investment in expressways, we find that there is a trade-off under various levels of relative risk aversion. Specifically, if relative risk aversion increases, efficiency decreases and intergenerational equity increases. Furthermore, when the level of technology increases, higher levels of both efficiency and intergenerational equity can be obtained through lifeextension investment in expressways.

The rest of this paper is organized as follows. In Section 2, we review the situation whereby aging expressway infrastructure has become a serious problem in Japan. In Section 3, we present a model for analyzing life-extension investment policies. In Section 4, we examine the relationship between efficiency and intergenerational equity associated with lifeextension investment in expressways using generational accounting. Section 5 concludes.

\section{Overview of Aging Expressway Infrastructure in Japan}

Since the Meishin Expressway connecting Kobe and Nagoya was opened in 1963, a network of expressways has been constructed throughout Japan. According to the Road Statistics Annual Report 2016 [20], the total length of expressways reached 8,652 km in April 2015. Thus, the number of expressways that have now been in use for a long time is increasing. Because risks are likely to increase as expressways continue to deteriorate, life-extension investment in expressways has become an issue of great concern.

Figure 1 shows changes in the total length of expressways and the average road age in Japan for the period 1962-2015. It is evident that the number of expressways that are more than 30 years old has increased remarkably since the 1990s, as has the number of expressways that are more than 40 years old since the 2000s. There is also an upward trend in the average road age for the period 1962-2015, with the average road age of expressways reaching approximately 26.7 years in April 2015. While the aging of Japan's population is wellknown, the aging of Japan's expressways is less well-known, but equally noteworthy.

Figure 2 shows the composition of expressway stock in terms of age as at April 2015. As can be seen in Figure 2, 43 percent of expressways in terms of total length were constructed at least 30 years ago. Further, for metropolitan 


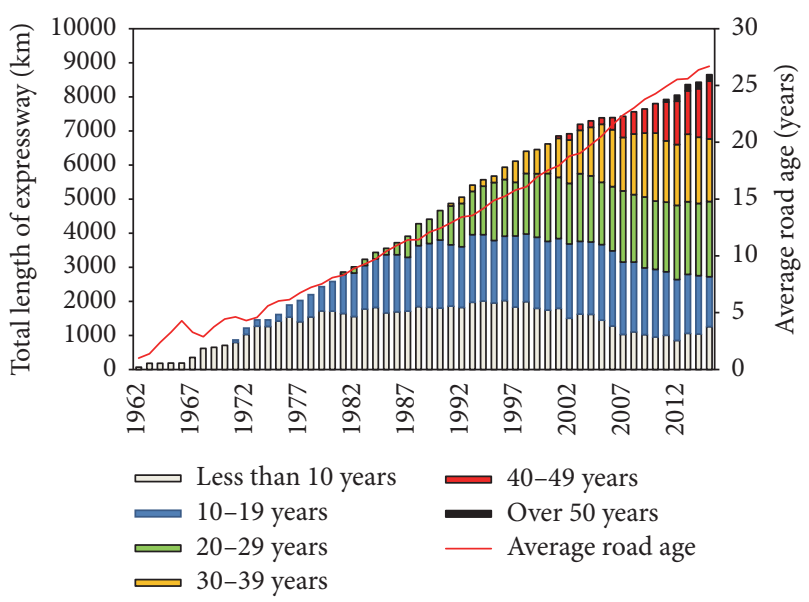

FIgURE 1: Total length of expressways and average road age. Source: Road Statistics Annual Report 2016, Ministry of Land, Infrastructure, Transport and Tourism, Japan.

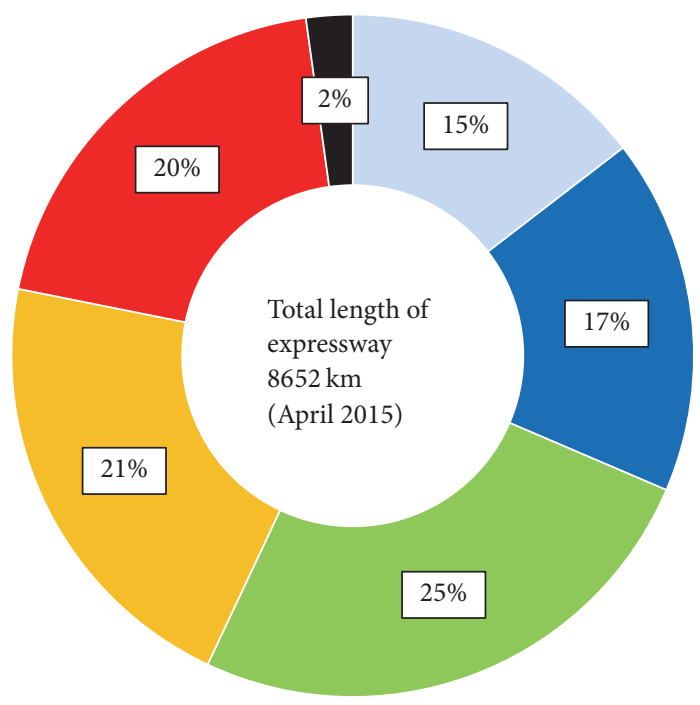

$\begin{array}{ll}\text { Less than } 10 \text { years } & 30-39 \text { years } \\ 10-19 \text { years } & 40-49 \text { years } \\ 20-29 \text { years } & \square \text { Over } 50 \text { years }\end{array}$

FIGURE 2: Expressway years of service. Source: Road Statistics Annual Report 2016, Ministry of Land, Infrastructure, Transport and Tourism, Japan.

expressways, this figure had risen to 56 percent by April 2017 [21]. Paper [22] pointed out that expressways that are more than 50 years old are expected to account for nearly 80 percent of the total length of expressways in Japan by 2050 , and thus there is growing fear of an increase in risks caused by longterm deterioration. Papers [23-25] have expressed concern about aging expressways in Japan from the perspective of infrastructure management.

It is clear that maintenance and renewal of infrastructure, including expressways, are important for sustained economic growth. Furthermore, as noted in [26], expressways can serve not only to enhance macroeconomic performance, but also to prevent disasters. In fact, expressways provided emergency alternative transport routes and acted as a breakwater during the tsunami following the Great East Japan Earthquake in 2011. Currently, Japan is facing the possibility of Nankai megathrust earthquakes at various points along the Nankai Trough, including directly beneath the Tokyo metropolitan area. Therefore, in an era of aging expressways, a life-extension investment policy for infrastructure, including expressways, is critical to the safety and security of the Japanese population.

Given the social and economic background in Japan, Nippon Expressway Company Limited (NEXCO), which is a group of three companies (NEXCO East, NEXCO Central, and NEXCO West) that was created following the privatization of the Japan Highway Public Corporation in 2005, set up the Technical Committee of the Method of the Long-Term Maintenance of Expressway Assets in November 2012 and has examined the "Long-Term Plan of Structural Replacement and Rehabilitation on Expressways in Japan" [22]. In addition, the Ministry of Land, Infrastructure, Transport and Tourism published their "Action Plans for Life Extension of Infrastructure" in May 2015.

\section{The Model}

3.1. The Basic Setup. Consider the circumstance in which the economy is run by a benevolent social planner who dictates the choices of consumption over time and seeks to maximize the utility of the household. We assume a closed economy populated by identical agents who consume a single commodity. There is no population growth and the labor force is equal to the population.

Time is discrete and indexed by $t=0,1,2, \ldots$ All decisions are taken at specified points in time. Let $Y_{t}$ be the flow of output, $C_{t}$ the aggregate consumption, $G_{t}$ the total amount of expressway stock as infrastructure, $K_{t}$ the capital stock other than expressways (nonexpressway capital), $\bar{L}$ the size of the working population, $I_{t}^{g}$ the investment in expressway stock, $I_{t}^{k}$ the investment in nonexpressway capital, and $M_{t}$ the expenditure on expressway maintenance.

The aggregate production function is given by

$$
Y_{t}=A G_{t}^{\alpha_{g}} K_{t}^{\alpha_{k}} \bar{L}^{1-\alpha_{k}},
$$

where $A$ represents the level of technology. We regard the level of technology as a parameter. In addition, $\alpha_{g}$ and $\alpha_{k}$ are parameters that satisfy $\alpha_{g}>0, \alpha_{k}>0$, and $\alpha_{g}+\alpha_{k}<1$. The form of the aggregate production function in (1) is similar to that in the model of [27]. However, in the model of [27], infrastructure is assumed to be constant over time.

The economy's resource constraint is given by

$$
Y_{t}=C_{t}+I_{t}^{k}+I_{t}^{g}+M_{t} .
$$

The net increase in the stock of nonexpressway capital at a given point in time equals gross investment less depreciation. Thus, the stock of nonexpressway capital evolves according to

$$
K_{t+1}-K_{t}=I_{t}^{k}-\delta_{k} K_{t}
$$


where $\delta_{k} \geq 0$ denotes the depreciation rate of nonexpressway capital.

\subsection{Dynamics of Expressway Infrastructure with Deteriora-} tion Vintage. We apply the Markov vintage modeling used in [3] to a representation of dynamic equations for the accumulation of expressway stock. Suppose that expressways are classified into $\bar{s}$ types depending on the deterioration vintage, which is indexed by $s=1,2, \ldots, \bar{s}$. Here, the term "deterioration vintage" can be interpreted as the degree of deterioration of infrastructure. A larger $s$ value means more advanced deterioration.

Let $g_{t}^{s}$ be the quantity of expressway with deterioration vintage $s$ at the beginning of period $t$. We consider that when the deterioration vintage becomes $\bar{s}$, the relevant expressway is retired. Hence, the value of the expressway with deterioration vintage $\bar{s}$ is zero. Furthermore, it is assumed that all expressways with different deterioration vintages provide the same service, irrespective of their deterioration vintage. Thus, there is no decrease in the value of an expressway as long as the deterioration vintage is between 1 and $\bar{s}-1$, even if the deterioration vintage becomes advanced. That is, the total amount of expressway infrastructure at the beginning of period $t$ equals the sum of expressway stock with deterioration vintage from 1 to $\bar{s}-1$ at the beginning of period $t$. Therefore, $G_{t}$ is given by

$$
G_{t}=\sum_{s=1}^{\bar{s}-1} g_{t}^{s}
$$

Assume that the deterioration vintage of expressways follows a Markov chain. For the expressway stock with deterioration vintage $s \in[2, \bar{s})$, we formulate

$$
\begin{aligned}
g_{t+1}^{s}=\phi_{s-1}\left(\frac{M_{t}}{G_{t}}\right) g_{t}^{s-1}+\left\{1-\phi_{s}\left(\frac{M_{t}}{G_{t}}\right)\right\} & g_{t}^{s}, \\
& (2 \leq s<\bar{s}) .
\end{aligned}
$$

The function $\phi_{s}\left(M_{t} / G_{t}\right)(1 \leq s<\bar{s})$ in (5) denotes the percentage shift to expressway stock with deterioration vintage $s+1$ per period in expressway stock with deterioration vintage $s$. Let $m$ be the intensity of maintenance of expressways (the ratio of expenditure on expressway maintenance to the total amount of expressway stock). Then, the expenditure on expressway maintenance equals $m G_{t}$. Paper [19] notes that the ratio of maintenance expenditure to infrastructure stock may be a more natural scaling variable than the ratio of maintenance expenditure to output, given that one would expect that the amount of maintenance depends on the prevailing stock of public infrastructure assets. For simplicity, we treat $m$ as a parameter. Note that (5) implies that $\phi_{s}$ is the Markov transition probability that represents the process of expressway deterioration. Specifically, we follow [3] by specifying $\phi_{s}(m)=\delta_{g} \exp (-\theta m)$, where $\delta_{g}>0$ and $\theta>0$ are parameters. It follows that $0<\phi_{s}(m)<1, d \phi_{s}(m) / d m<0$, and $d^{2} \phi_{s}(m) / d m^{2}>0$ hold. When $s=1, g_{t+1}^{1}$ is given by

$$
g_{t+1}^{1}=I_{t}^{g}+\left\{1-\phi_{1}\left(\frac{M_{t}}{G_{t}}\right)\right\} g_{t}^{1} .
$$

3.3. The Social Planner's Problem. The social welfare function is defined as follows:

$$
W_{0}=\sum_{t=0}^{\infty} \beta^{t} \bar{L} u\left(\frac{C_{t}}{\bar{L}}\right)
$$

where $\beta \in(0,1)$ is the discount factor and $c_{t}=C_{t} / \bar{L}$ is consumption per worker. The social planner chooses a stream of consumption per worker $\left\{c_{t}\right\}_{t=0}^{\infty}$ so as to maximize the social welfare in (7). The utility function $u(c)$ takes the constant relative risk aversion form

$$
u(c)= \begin{cases}\frac{c^{1-\sigma}-1}{1-\sigma}, & (\sigma \neq 1), \\ \ln c, & (\sigma=1) .\end{cases}
$$

In (8), parameter $\sigma>0$ is the Arrow-Pratt coefficient of relative risk aversion, which is defined as $-c u^{\prime \prime}(c) / u^{\prime}(c)$, and assumed to be constant. The higher the value of $\sigma$, the more rapid the proportionate decline in $u^{\prime}(c)$ in response to an increase in $c$, and hence the lower the willingness of households to accept deviations from a uniform pattern of $c$ over time. In addition, $\sigma$ can be regarded as a measure of intergenerational equity in the context of a life-extension investment policy for infrastructure because the concavity of $u(c)$ means that households prefer a relatively uniform pattern to one in which $c$ exhibits volatility ranging from very low to very high.

Given $K_{0}$ and $\left\{g_{0}^{s}\right\}_{s=1}^{\bar{s}-1}$, the social planner's problem is to maximize $W_{0}$ in (7), subject to (1) to (6). To solve the social planner's problem, we set the Lagrange function $\mathscr{L}_{0}$ as follows:

$$
\begin{aligned}
\mathscr{L}_{0} & =\sum_{t=0}^{\infty} \beta^{t}\left[\bar{L} \frac{\left(C_{t} / \bar{L}\right)^{1-\sigma}-1}{1-\sigma}\right. \\
& +\lambda_{t}\left(A G_{t}^{\alpha_{g}} K_{t}^{\alpha_{k}} \bar{L}^{1-\alpha_{k}}-C_{t}-I_{t}^{k}-I_{t}^{g}-m G_{t}\right) \\
& +\chi_{t}^{k}\left\{I_{t}^{k}+\left(1-\delta_{k}\right) K_{t}-K_{t+1}\right\}+\xi_{t}\left(\sum_{s=1}^{\bar{s}-1} g_{t}^{s}-G_{t}\right) \\
& +\chi_{t}^{g, 1}\left[I_{t}^{g}+\left\{1-\phi_{1}(m)\right\} g_{t}^{1}-g_{t+1}^{1}\right] \\
& \left.+\sum_{s=2}^{\bar{s}-1} \chi_{t}^{g, s}\left[\phi_{s-1}(m) g_{t}^{s-1}+\left\{1-\phi_{s}(m)\right\} g_{t}^{s}-g_{t+1}^{s}\right]\right]
\end{aligned}
$$

where $\lambda_{t}, \chi_{t}^{k}, \chi_{t}^{g, s}(1 \leq s \leq \bar{s})$, and $\xi_{t}$ are Lagrange multipliers. From (9), the resulting first-order conditions can then be 
derived as follows:

$$
\begin{aligned}
& \lambda_{t}=\left(\frac{C_{t}}{\bar{L}}\right)^{-\sigma}, \\
& \lambda_{t}= \chi_{t}^{k}, \\
& \lambda_{t}= \chi_{t}^{g, 1}, \\
& \lambda_{t} G_{t}=-\chi_{t}^{g, 1} \phi_{1}^{\prime}\left(\frac{M_{t}}{G_{t}}\right) g_{t}^{1} \\
&+\sum_{s=2}^{\bar{s}-1} \chi_{t}^{g, s}\left\{\phi_{s-1}^{\prime}\left(\frac{M_{t}}{G_{t}}\right) g_{t}^{s-1}-\phi_{s}^{\prime}\left(\frac{M_{t}}{G_{t}}\right) g_{t}^{s}\right\} \\
& \bar{s}-2 \\
&= \sum_{s=1}\left\{-g_{t}^{s} \phi_{s}^{\prime}(m)\left(\chi_{t}^{g, s}-\chi_{t}^{g, s+1}\right)\right\} \\
&-g_{t}^{\bar{s}-1} \phi_{\bar{s}-1}^{\prime}(m) \chi_{t}^{g, \bar{s}^{-1}}, \\
& \chi_{t}^{g, \bar{s}-1}= \beta \xi_{t+1}+\beta \chi_{t+1}^{g, \bar{s}^{-1}}\left\{1-\phi_{\bar{s}-1}(m)\right\} . \\
& \xi_{t}= \lambda_{t}\left(\alpha_{g} A G_{t}^{\alpha_{g}-1} K_{t}^{\alpha_{k}} \bar{L}^{1-\alpha_{k}}-m\right), \\
& \chi_{t}^{k}= \beta \lambda_{t+1} \alpha_{k} A G_{t+1}^{\alpha_{g}} K_{t+1}^{\alpha_{k}-1} \bar{L}^{1-\alpha_{k}}+\beta \chi_{t+1}^{k}\left(1-\delta_{k}\right), \\
& \chi_{t}^{g, s}= \beta \xi_{t+1}+\beta \chi_{t+1}^{g, s}\left\{1-\phi_{s}(m)\right\}+\beta \chi_{t+1}^{g, s+1} \phi_{s}(m), \\
&(1 \leq s \leq \bar{s}-2),
\end{aligned}
$$

Note that (13) implies that the optimal level of lifeextension investment satisfies the condition whereby the marginal benefit is equal to the marginal cost of life-extension investment. With regard to $\chi_{t}^{g, s}$ on the left-hand side of (16) and $\chi_{t}^{g, \bar{s}-1}$ on the left-hand side of (17), $\chi_{t}^{g, s}$ and $\chi_{t}^{g, \bar{s}-1}$ mean the values of expressways at the beginning of period $t$ with deterioration vintages $s$ and $\bar{s}-1$, respectively.

We now focus on the steady state, in which variables in the model grow at nonnegative constant rates, and examine the effects of the intensity of expressway maintenance, $m$, on macroeconomic performance. We express the steady-state values of $Y_{t}, C_{t}, K_{t}, G_{t}, I_{t}^{k}, I_{t}^{g}$, and $g_{t}^{1}$ as $Y^{*}, C^{*}, K^{*}, G^{*}, I^{k *}, I^{g^{*}}$, and $g^{1 *}$, respectively. Here, as in [3], there are two cases in relation to deterioration vintage, that is, $s=1,2$ : "usable," because the expressway is not yet retired when $s=1$, and "unusable," because the expressway is retired in the sense of reaching its serviceability limit when $s=2$. This implies that $\bar{s}=2$ in (4). Hence, $G_{t}=g_{t}^{1}$ holds. As a result, $Y^{*}, C^{*}, K^{*}, G^{*}, I^{k *}, I^{g *}$, and $g^{1 *}$ are constant over time (see Appendix A for the proof). In other words, the growth rates of $Y_{t}, C_{t}, K_{t}, G_{t}, I_{t}^{k}, I_{t}^{g}$, and $g_{t}^{1}$ in the steady state are 0 .

In the steady state of the model, the following relationships hold:

$$
\begin{aligned}
& 1=\beta \alpha_{k} A G^{* \alpha_{g}} K^{* \alpha_{k}-1} \bar{L}^{1-\alpha_{k}}+\beta\left(1-\delta_{k}\right), \\
& 1=\beta \alpha_{g} A G^{* \alpha_{g}-1} K^{* \alpha_{k}} \bar{L}^{1-\alpha_{k}}-\beta m+\beta\left\{1-\phi_{1}(m)\right\} .
\end{aligned}
$$

See Appendix B for the derivations of (18) and (19).
Define the functions $\mathscr{F}\left(G^{*}, K^{*}, m\right)$ and $\mathscr{H}\left(G^{*}, K^{*}, m\right)$ as follows:

$$
\begin{aligned}
\mathscr{F}\left(G^{*}, K^{*}, m\right)= & \beta \alpha_{k} A G^{* \alpha_{g}} K^{* \alpha_{k}-1} \bar{L}^{1-\alpha_{k}}+\beta\left(1-\delta_{k}\right) \\
& -1, \\
\mathscr{H}\left(G^{*}, K^{*}, m\right)= & \beta \alpha_{g} A G^{* \alpha_{g}-1} K^{* \alpha_{k}} \bar{L}^{1-\alpha_{k}}-\beta m \\
& +\beta\left\{1-\phi_{1}(m)\right\}-1 .
\end{aligned}
$$

Totally differentiating (20) with respect to $G^{*}, K^{*}$, and $m$, we obtain

$$
\begin{aligned}
d \mathscr{F}= & \left\{\left(\alpha_{k}-1\right) \beta \alpha_{k} A G^{* \alpha_{g}} K^{* \alpha_{k}-2} \bar{L}^{1-\alpha_{k}}\right\} d K^{*} \\
& +\left(\alpha_{g} \beta \alpha_{k} A G^{* \alpha_{g}-1} K^{* \alpha_{k}-1} \bar{L}^{1-\alpha_{k}}\right) d G^{*}=0 .
\end{aligned}
$$

In addition, totally differentiating (21) with respect to $G^{*}, K^{*}$, and $m$, we get

$$
\begin{aligned}
d \mathscr{H}= & \left(\alpha_{k} \beta \alpha_{g} A G^{* \alpha_{g}-1} K^{* \alpha_{k}-1} \bar{L}^{1-\alpha_{k}}\right) d K^{*} \\
& +\left\{\left(\alpha_{g}-1\right) \beta \alpha_{g} A G^{* \alpha_{g}-2} K^{* \alpha_{k}} \bar{L}^{1-\alpha_{k}}\right\} d G^{*} \\
& +\left[-\beta\left\{1+\phi_{1}^{\prime}(m)\right\}\right] d m=0 .
\end{aligned}
$$

Multiplying both sides of (22) by $\left(\alpha_{g}-1\right)$ yields

$$
\begin{aligned}
& \left(\alpha_{g}-1\right)\left\{\left(\alpha_{k}-1\right) \beta \alpha_{k} A G^{* \alpha_{g}} K^{* \alpha_{k}-2} \bar{L}^{1-\alpha_{k}}\right\} d K^{*} \\
& =-\left(\alpha_{g}-1\right)\left(\alpha_{g} \beta \alpha_{k} A G^{* \alpha_{g}-1} K^{* \alpha_{k}-1} \bar{L}^{1-\alpha_{k}}\right) d G^{*} .
\end{aligned}
$$

Moreover, multiplying both sides of (23) by $\left(\alpha_{k} G^{*} / K^{*}\right)$ leads to

$$
\begin{aligned}
\left(\frac{\alpha_{k} G^{*}}{K^{*}}\right)\left(\alpha_{k} \beta \alpha_{g} A G^{* \alpha_{g}-1} K^{* \alpha_{k}-1} \bar{L}^{1-\alpha_{k}}\right) d K^{*} \\
=-\left(\frac{\alpha_{k} G^{*}}{K^{*}}\right) \\
\quad \times\left\{\left(\alpha_{g}-1\right) \beta \alpha_{g} A G^{* \alpha_{g}-2} K^{* \alpha_{k}} \bar{L}^{1-\alpha_{k}}\right\} d G^{*} \\
-\left(\frac{\alpha_{k} G^{*}}{K^{*}}\right)\left[-\beta\left\{1+\phi_{1}^{\prime}(m)\right\}\right] d m .
\end{aligned}
$$

Considering (24) and (25), we have

$$
\begin{gathered}
\left\{\left(\alpha_{g}-1\right)\left(\alpha_{k}-1\right) \beta A G^{* \alpha_{g}} K^{* \alpha_{k}-2} \bar{L}^{1-\alpha_{k}}\right. \\
\left.-\alpha_{k} \alpha_{k} \beta \alpha_{g} A G^{* \alpha_{g}} K^{* \alpha_{k}-2} \bar{L}^{1-\alpha_{k}}\right\} d K^{*} \\
=\frac{\alpha_{k} G^{*}}{K^{*}}\left\{-\beta-\beta \phi_{1}^{\prime}(m)\right\} d m .
\end{gathered}
$$

From (26), we obtain

$$
\frac{d K^{*}}{d m}=-\left(\frac{1}{1-\alpha_{k}-\alpha_{g}}\right) \frac{1+\phi_{1}^{\prime}(m)}{\alpha_{g} A G^{* \alpha_{g}-1} K^{* \alpha_{k}-1} \bar{L}^{1-\alpha_{k}}} .
$$


Multiplying both sides of (22) by $\left(\alpha_{g} G^{*} / K^{*}\right)$ yields

$$
\begin{aligned}
& \left(\frac{\alpha_{g} K^{*}}{G^{*}}\right)\left\{\left(\alpha_{k}-1\right) \beta \alpha_{k} A G^{* \alpha_{g}} K^{* \alpha_{k}-2} \bar{L}^{1-\alpha_{k}}\right\} d K^{*} \\
& =-\left(\frac{\alpha_{g} K^{*}}{G^{*}}\right)\left(\alpha_{g} \beta \alpha_{k} A G^{* \alpha_{g}-1} K^{* \alpha_{k}-1} \bar{L}^{1-\alpha_{k}}\right) d G^{*}
\end{aligned}
$$

Furthermore, multiplying both sides of (23) by $\left(\alpha_{k}-1\right)$ leads to

$$
\begin{aligned}
& \left(\alpha_{k}-1\right)\left\{\alpha_{k} \beta \alpha_{g} A G^{* \alpha_{g}-1} K^{* \alpha_{k}-1} \bar{L}^{1-\alpha_{k}}\right\} d K^{*} \\
& =-\left(\alpha_{k}-1\right)\left\{\left(\alpha_{g}-1\right) \beta \alpha_{g} A G^{* \alpha_{g}-2} K^{* \alpha_{k}} \bar{L}^{1-\alpha_{k}}\right\} d G^{*} \\
& \quad-\left(\alpha_{k}-1\right)\left[-\beta\left\{1+\phi_{1}^{\prime}(m)\right\}\right] d m .
\end{aligned}
$$

Using (28) and (29), we get

$$
\begin{aligned}
& \left\{\alpha_{g}^{2} \beta \alpha_{k} A G^{* \alpha_{g}-2} K^{* \alpha_{k}} \bar{L}^{1-\alpha_{k}}-\left(\alpha_{g}-1\right)\left(\alpha_{k}-1\right)\right. \\
& \left.\quad \times \beta \alpha_{g} A G^{* \alpha_{g}-2} K^{* \alpha_{k}} \bar{L}^{1-\alpha_{k}}\right\} d G^{*}=\left(\alpha_{k}-1\right) \\
& \quad \times\left\{-\beta-\beta \phi_{1}^{\prime}(m)\right\} d m .
\end{aligned}
$$

Then, (30) implies that

$$
\frac{d G^{*}}{d m}=-\left(\frac{1-\alpha_{k}}{1-\alpha_{k}-\alpha_{g}}\right) \frac{1+\phi_{1}^{\prime}(m)}{\alpha_{g} A G^{* \alpha_{g}-2} K^{* \alpha_{k}} \bar{L}^{1-\alpha_{k}}} .
$$

For convenience, we assume that $-\phi_{1}^{\prime}(m)>1$. Then, we find that the relationships $d K^{*} / d m>0$ and $d G^{*} / d m>0$ hold from (27) and (31), respectively.

In the steady state, (3) implies that $I^{k *}=\delta_{k} K^{*}$. This result and (27) lead to

$$
\begin{aligned}
\frac{d I^{k *}}{d m} & =\delta_{k} \frac{d K^{*}}{d m} \\
& =-\left(\frac{\delta_{k}}{1-\alpha_{k}-\alpha_{g}}\right) \frac{1+\phi_{1}^{\prime}(m)}{A G^{* \alpha_{g}-1} K^{* \alpha_{k}-1} \bar{L}^{1-\alpha_{k}}}>0 .
\end{aligned}
$$

The relationships in (4), (5), and (31) imply that

$$
\begin{gathered}
\frac{d I^{g *}}{d m}=\phi_{1}^{\prime}(m) G^{*}+\phi_{1}(m) \frac{d G^{*}}{d m}=\left[\phi_{1}^{\prime}(m) G^{*}\right. \\
\left.-\left(\frac{1-\alpha_{k}}{1-\alpha_{k}-\alpha_{g}}\right) \frac{\phi_{1}(m)\left\{1+\phi_{1}^{\prime}(m)\right\}}{\alpha_{g} A G^{* \alpha_{g}-2} K^{*} \alpha_{k} \bar{L}^{1-\alpha_{k}}}\right] .
\end{gathered}
$$

Recall that $\phi_{1}^{\prime}(m)<0$ and $d G^{*} / d m>0$. Consequently, the sign of $d I^{g *} / d m$ in (33) is ambiguous. In addition, $M^{*}=$ $m G^{*}$ and (31) imply that

$$
\begin{aligned}
& \frac{d M^{*}}{d m}=G^{*}+m \frac{d G^{*}}{d m} \\
& =\left\{G^{*}-m\left(\frac{1-\alpha_{k}}{1-\alpha_{k}-\alpha_{g}}\right) \frac{1+\phi_{1}^{\prime}(m)}{\alpha_{g} A G^{* \alpha_{g}-2} K^{*} \alpha_{k} \bar{L}^{1-\alpha_{k}}}\right\}
\end{aligned}
$$

$>0$.

In addition, from (1), (27), and (31), we obtain

$$
\begin{aligned}
\frac{d Y^{*}}{d m}= & \alpha_{k} A G^{* \alpha_{g}} K^{* \alpha_{k}-1} \bar{L}^{1-\alpha_{k}} \frac{d K^{*}}{d m} \\
& +\alpha_{g} A G^{* \alpha_{g}-1} K^{* \alpha_{k}} \bar{L}^{1-\alpha_{k}} \frac{d G^{*}}{d m} \\
= & -\frac{1+\phi_{1}^{\prime}(m)}{1-\alpha_{k}-\alpha_{g}} G^{*}>0 .
\end{aligned}
$$

Furthermore, (2), together with (32) to (35), implies that

$$
\begin{aligned}
\frac{d C^{*}}{d m} & =\frac{d Y^{*}}{d m}-\frac{d I^{k *}}{d m}-\frac{d I^{g *}}{d m}-\frac{d M^{*}}{d m} \\
& =\left\{-\frac{1+\phi_{1}^{\prime}(m)}{1-\alpha_{k}-\alpha_{g}} G^{*}\right\} \\
& -\left\{-\left(\frac{\delta_{k}}{1-\alpha_{k}-\alpha_{g}}\right) \frac{1+\phi_{1}^{\prime}(m)}{A G^{* \alpha_{g}-1} K^{* \alpha_{k}-1} \bar{L}^{1-\alpha_{k}}}\right\} \\
& -\left[\phi_{1}^{\prime}(m) G^{*}\right. \\
& \left.-\left(\frac{1-\alpha_{k}}{1-\alpha_{k}-\alpha_{g}}\right) \frac{\phi_{1}\left\{1+\phi_{1}^{\prime}(m)\right\}}{\alpha_{g} A G^{* \alpha_{g}-2} K^{* \alpha_{k}} \bar{L}^{1-\alpha_{k}}}\right]-\left\{G^{*}\right. \\
& \left.-m\left(\frac{1-\alpha_{k}}{1-\alpha_{k}-\alpha_{g}}\right) \frac{1+\phi_{1}^{\prime}(m)}{\alpha_{g} A G^{* \alpha_{g}-2} K^{* \alpha_{k}} \bar{L}^{1-\alpha_{k}}}\right\} \\
& =-\frac{1+\phi_{1}^{\prime}(m)}{1-\alpha_{k}-\alpha_{g}}\left(\frac{1}{A G^{* \alpha_{g}-1} K^{* \alpha_{k}} \bar{L}^{1-\alpha_{k}}}\right) \\
& \times\left[\left(1-\alpha_{k}-\alpha_{g}\right) A G^{* \alpha_{g}} K^{* \alpha_{k}} \bar{L}^{1-\alpha_{k}}-\delta_{k} K^{*}\right. \\
& \left.-\frac{1-\alpha_{k}}{\alpha_{g}} G^{*}\left\{\phi_{1}(m)+m\right\}\right] .
\end{aligned}
$$


We can use (18) and (19) to obtain

$$
\begin{gathered}
\delta_{k} K^{*}=\alpha_{k} A G^{* \alpha_{g}} K^{* \alpha_{k}} \bar{L}^{1-\alpha_{k}}-\left(\frac{1}{\beta}-1\right) K^{*}, \\
\frac{1-\alpha_{k}}{\alpha_{g}} G^{*}\left\{\phi_{1}(m)+m\right\} \\
=\left(1-\alpha_{k}\right) \alpha_{k} A G^{* \alpha_{g}} K^{* \alpha_{k}} \bar{L}^{1-\alpha_{k}} \\
-\frac{1-\alpha_{k}}{\alpha_{g}}\left(\frac{1}{\beta}-1\right) G^{*} .
\end{gathered}
$$

Substituting (37) and (38) into (36) yields

$$
\begin{aligned}
& \frac{d C^{*}}{d m}=-\frac{1+\phi_{1}^{\prime}(m)}{1-\alpha_{k}-\alpha_{g}}\left(\frac{1}{A G^{* \alpha_{g}-1} K^{* \alpha_{k}} \bar{L}^{1-\alpha_{k}}}\right) \\
& \quad \times\left\{\left(1-\alpha_{k}-\alpha_{g}\right) A G^{* \alpha_{g}} K^{* \alpha_{k}} \bar{L}^{1-\alpha_{k}}\right. \\
& \left.+\left(\frac{1}{\beta}-1\right)\left(K^{*}+\frac{1-\alpha_{k}}{\alpha_{g}} G^{*}\right)\right\}>0 .
\end{aligned}
$$

Recall that the working population, $\bar{L}$, is assumed to be constant. For consumption per worker in the steady state, $c^{*} \equiv C^{*} / \bar{L}$, hence it follows that $d c^{*} / d m>0$ from the result of (39).

\section{Numerical Analysis}

4.1. Effects of Life-Extension Investment. We now numerically examine the effects of investment to extend the life of expressways. Let $\widehat{c}_{t}\left(m_{i}\right)$ be the consumption per worker in the case of maintenance intensity $m_{i}$ in period $t$ on the optimal growth path and $\widehat{W}\left(m_{i}\right)$ be the social welfare obtained from $\left\{\widehat{c}_{t}\left(m_{i}\right)\right\}_{t=0}^{\infty}$. Therefore, $\widehat{W}\left(m_{i}\right)$ is given by

$$
\widehat{W}\left(m_{i}\right)= \begin{cases}\sum_{t=0}^{\infty} \beta^{t} \bar{L} \frac{\left\{\widehat{c}_{t}\left(m_{i}\right)\right\}^{1-\sigma}-1}{1-\sigma}, & (\sigma \neq 1), \\ \sum_{t=0}^{\infty} \beta^{t} \bar{L} \ln \widehat{c}_{t}\left(m_{i}\right), & (\sigma=1) .\end{cases}
$$

As in [28], the benefit of life-extension investment in expressways $V\left(m_{i}, m_{j}\right)$ is defined as the difference between $\widehat{W}\left(m_{i}\right)$ and $\widehat{W}\left(m_{j}\right)(i \neq j)$ :

$$
\begin{aligned}
& V\left(m_{i}, m_{j}\right)=\widehat{W}\left(m_{i}\right)-\widehat{W}\left(m_{j}\right) \\
& = \begin{cases}\sum_{t=0}^{\infty} \beta^{t} \bar{L} \frac{\left\{\widehat{c}_{t}\left(m_{i}\right)\right\}^{1-\sigma}-1}{1-\sigma}-\sum_{t=0}^{\infty} \beta^{t} \bar{L} \frac{\left\{\widehat{c}_{t}\left(m_{j}\right)\right\}^{1-\sigma}-1}{1-\sigma}, & (\sigma \neq 1), \\
\sum_{t=0}^{\infty} \beta^{t} \bar{L} \ln \widehat{c}_{t}\left(m_{i}\right)-\sum_{t=0}^{\infty} \beta^{t} \bar{L} \ln \widehat{c}_{t}\left(m_{j}\right), & (\sigma=1) .\end{cases}
\end{aligned}
$$

Moreover, let $c^{*}\left(m_{i}\right)$ be the consumption per worker in the case of maintenance intensity $m_{i}$ in the steady state. The social welfare obtained from $\left\{c^{*}\left(m_{i}\right)\right\}_{t=0}^{\infty}, W^{*}\left(m_{i}\right)$, in the steady state is given by

$$
\begin{aligned}
& W^{*}\left(m_{i}\right) \\
& =\left\{\begin{array}{cc}
\sum_{t=0}^{\infty} \beta^{t} \bar{L} \frac{\left\{c^{*}\left(m_{i}\right)\right\}^{1-\sigma}-1}{1-\sigma} & \\
=\frac{1}{1-\beta} \bar{L} \frac{\left\{c^{*}\left(m_{i}\right)\right\}^{1-\sigma}-1}{1-\sigma}, & (\sigma \neq 1), \\
\sum_{t=0}^{\infty} \beta^{t} \bar{L} \ln \left\{c^{*}\left(m_{i}\right)\right\} & (\sigma=1) . \\
=\frac{1}{1-\beta} \bar{L} \ln \left\{c^{*}\left(m_{i}\right)\right\}, &
\end{array}\right.
\end{aligned}
$$

Let ST be the stock effect and SM the smoothing effect. The stock effect means that room for new investment is created by life-extension investment in expressway stock, and therefore economic growth can be promoted through capital accumulation. The smoothing effect means that the dynamic path of consumption per worker is smoothed by life-extension investment in expressway stock and results in greater social welfare (for details, see [3]).

Based on (40) and (42), the welfare loss, $\mathrm{LO}\left(m_{i}\right)$, when maintenance intensity is $m_{i}$ can be written as

$$
\operatorname{LO}\left(m_{i}\right)=W^{*}\left(m_{i}\right)-\widehat{W}\left(m_{i}\right) \text {. }
$$

If we consider maintenance intensities $m_{i}$ and $m_{j}(i \neq j)$, the smoothing effect $\operatorname{SM}\left(m_{i}, m_{j}\right)$ is measured by the difference between $\operatorname{LO}\left(m_{i}\right)$ and $\operatorname{LO}\left(m_{j}\right)$. That is, $\operatorname{SM}\left(m_{i}, m_{j}\right)$ is given by

$$
\operatorname{SM}\left(m_{i}, m_{j}\right)=\operatorname{LO}\left(m_{i}\right)-\mathrm{LO}\left(m_{j}\right),
$$

where $\mathrm{LO}\left(m_{i}\right)$ and $\mathrm{LO}\left(m_{j}\right)$ are calculated using (43).

In our model, the benefits of life-extension investment in expressways can be decomposed into the stock effect and the smoothing effect. Therefore, when we express the stock effect for $m_{i}$ and $m_{j}(i \neq j)$ as ST $\left(m_{i}, m_{j}\right)$, the following relationship holds:

$$
V\left(m_{i}, m_{j}\right)=\operatorname{SM}\left(m_{i}, m_{j}\right)+\operatorname{ST}\left(m_{i}, m_{j}\right) .
$$

Substituting the life-extension benefits from (41) and the smoothing effect from (44) into (45) yields the stock effect $\mathrm{ST}\left(m_{i}, m_{j}\right)$. In accordance with data from [29, 30], we set $\left(G_{0}, K_{0}\right)=(835.8,1261.0)$. For simplicity, investment in nonexpressway stock is fixed at $I_{t}^{k}=285$. The baseline settings for the key parameter values are as follows: $\delta_{g}=1.00$, $\delta_{k}=0.10, \theta=100, A=1.00, \beta=\exp (-0.15), \alpha_{k}=0.35$, $\alpha_{g}=0.10$, and $\bar{L}=1000$.

We investigate the data for expressway investment in Japan from [31]. Figure 3 shows expressway investment in Japan for 10 subperiods over the period 1963-2012. When we look at the changes in expressway investment shown in Figure 3, we find that there are some remarkable fluctuations. In our numerical analysis, the deterioration vintage value declines steadily from 10 in the subperiod from 1963 to 1967 to 1 in the subperiod from 2008 to 2012 . 


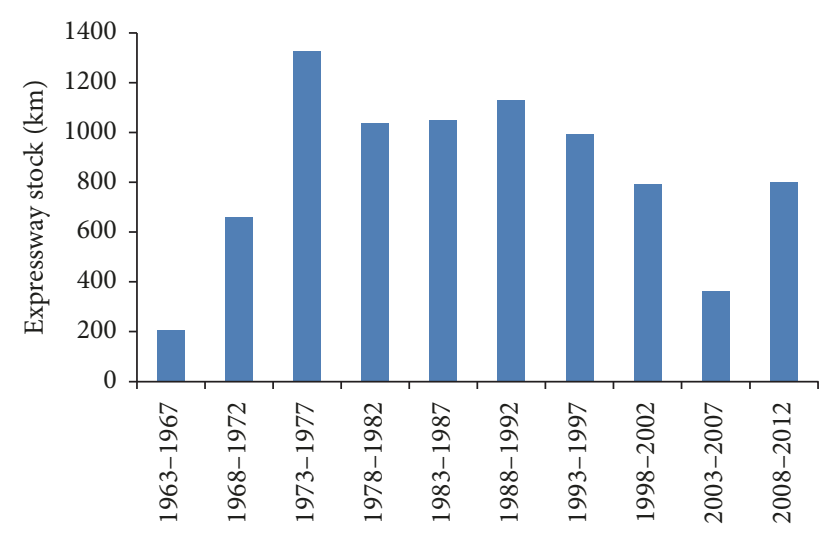

FIGURE 3: Expressway investment in Japan. Source: Road Statistics Annual Report 2015, Ministry of Land, Infrastructure, Transport and Tourism, Japan.

To compare the effects of life-extension investment policies, we consider different values of maintenance intensity, that is, $m_{1}=0.016$ and $m_{2}=0.020$. Under the conditions $\delta_{g}=1.00, \theta=100$, and $g_{1}^{1}=1$, when $m_{1}=0.016$, we obtain the expected value of around 50 years for the period until the expressway stock reaches its serviceability limit. The value of 50 years is consistent with the preliminary calculation by [32] that the average useful life of roads, which include both general roads and expressways, is 48 years in Japan. On the other hand, if $m_{2}=0.020$, we obtain the expected value of about 70 years for the period before the expressway stock reaches its serviceability limit.

In calculating the values of $\operatorname{SM}\left(m_{2}, m_{1}\right), \operatorname{ST}\left(m_{2}, m_{1}\right)$, and $V\left(m_{2}, m_{1}\right)$ corresponding to maintenance intensity values $m_{1}=0.016$ and $m_{2}=0.020$, we consider relative risk aversion (RRA) values from 1.00 to 2.30. In [33], the degree of relative risk aversion (RRA) is estimated and the hypothesis of constant relative risk aversion (CRRA) is examined for 15 developed countries. For Japan, [33] estimates an RRA of 2.76 using an approximate demand-for-insurance function and notes that the CRRA hypothesis cannot be rejected. Paper [34] estimates an RRA for Japan of between 1 and 2 using a consumption demand function.

Tables 1-5 show the total benefits, the smoothing effect, and the stock effect when $A=1.00,1.25,1.50,1.75$, and 2.00, respectively.

Given a level of technology, the relationship whereby the sum of the smoothing effect and the stock effect is equal to the total benefits implies that

$$
\frac{\text { smoothing effect }}{\text { total benefits }}+\frac{\text { stock effect }}{\text { total benefits }}=1 \text {. }
$$

In (46), the first term and the second term on the lefthand side are the ratio of the contribution of the smoothing effect and the ratio of the contribution of the stock effect, respectively. Focusing on RRA $=2.00$ in Table 1 as an illustration, it can be seen that the ratio of contribution of the smoothing effect is 0.066 and that of the stock effect is 0.934 . Therefore, when RRA $=2.00$, the contributions of the smoothing effect and the stock effect to the total benefits are 6.6 percent and 93.4 percent, respectively.

Considering the results shown in Tables 1-5, we find that there are some common characteristics in the cases where $A=1.00,1.25,1.50,1.75$, and 2.00. The contribution of the stock effect is more than 90 percent, while the contribution of the smoothing effect is less than 10 percent, for each value of $A$. That is, the benefits of life-extension investment in expressways are mostly attributable to the stock effect. Intuitively, this result can be explained as follows. A lower RRA value means a greater willingness to save. Consequently, capital accumulation and economic growth are promoted. This results in greater benefits from life-extension investment in expressways. Furthermore, the smoothing effect and the stock effect are both higher when RRA is low. Because the benefits of life-extension investment consist of both a smoothing effect and a stock effect, this implies that if RRA is low, the life-extension benefits are high.

In contrast, we find the following differences among Tables 1-5. Let us focus on the case where RRA $=2.00$ in each table; that is, the relevant values (smoothing effect, stock effect, and total benefits) are $(0.282,3.975$, and 4.257$)$ in Table $1,(0.200,2.662$, and 2.862$)$ in Table $2,(0.148,1.973$, and 2.121) in Table $3,(0.114,1.556$, and 1.670$)$ in Table 4 , and $(0.091$, 1.280 , and 1.371) in Table 5. It can be seen from Tables $1-5$ that when the technology parameter is large, the smoothing effect, the stock effect, and the total benefits are all low. This is also true in relation to other RRA values. Hence, the higher the level of technology, the lower the life-extension benefits. In other words, the difference between social welfare $\widehat{W}(0.200)$ when maintenance intensity $m_{2}=0.200$ and social welfare $\widehat{W}(0.016)$ when maintenance intensity $m_{1}=0.016$ becomes smaller as the level of technology increases. These results suggest that the welfare-enhancing effect of technological progress decreases with the level of technology. Moreover, it can be confirmed that there is a difference in movement of total benefits among Tables 1-5. We now express the total benefits when RRA $=x$ as $B_{x}$ and define the index of total benefits when RRA $=x$ as $\left(B_{x} / B_{1.00}\right) \times 100$. For example, in the case of $A=1.00$, the index of total benefits when RRA $=1.05$ becomes 97.3. Figure 4 shows changes in the index of total benefits in the cases where $A=1.00,1.25,1.50$, 1.75 , and 2.00 .

As can be seen in Figure 4, when the technology parameter is larger, the index of total benefits shows a more rapid decline in association with an increase in RRA.

For the cases where $m_{1}=0.016$ and $m_{2}=0.020$, Figure 5 shows the movements of total expenditure on expressways $\left(I_{t}^{g}+M_{t}\right)$, consisting of investment in replacement expressway stock and expenditure on expressway maintenance. It can be seen that, in the cases where $m_{1}=0.016$ and $m_{2}=0.020$, the fluctuations in total expenditure on expressways are initially relatively large and then gradually decrease. This behavior is caused by differences in the deterioration vintage of expressways in each period. Specifically, investment to renew older expressways initially increases until it reaches a peak and then gradually decreases. These cyclical fluctuations in the transition process cause total expenditure on expressways 


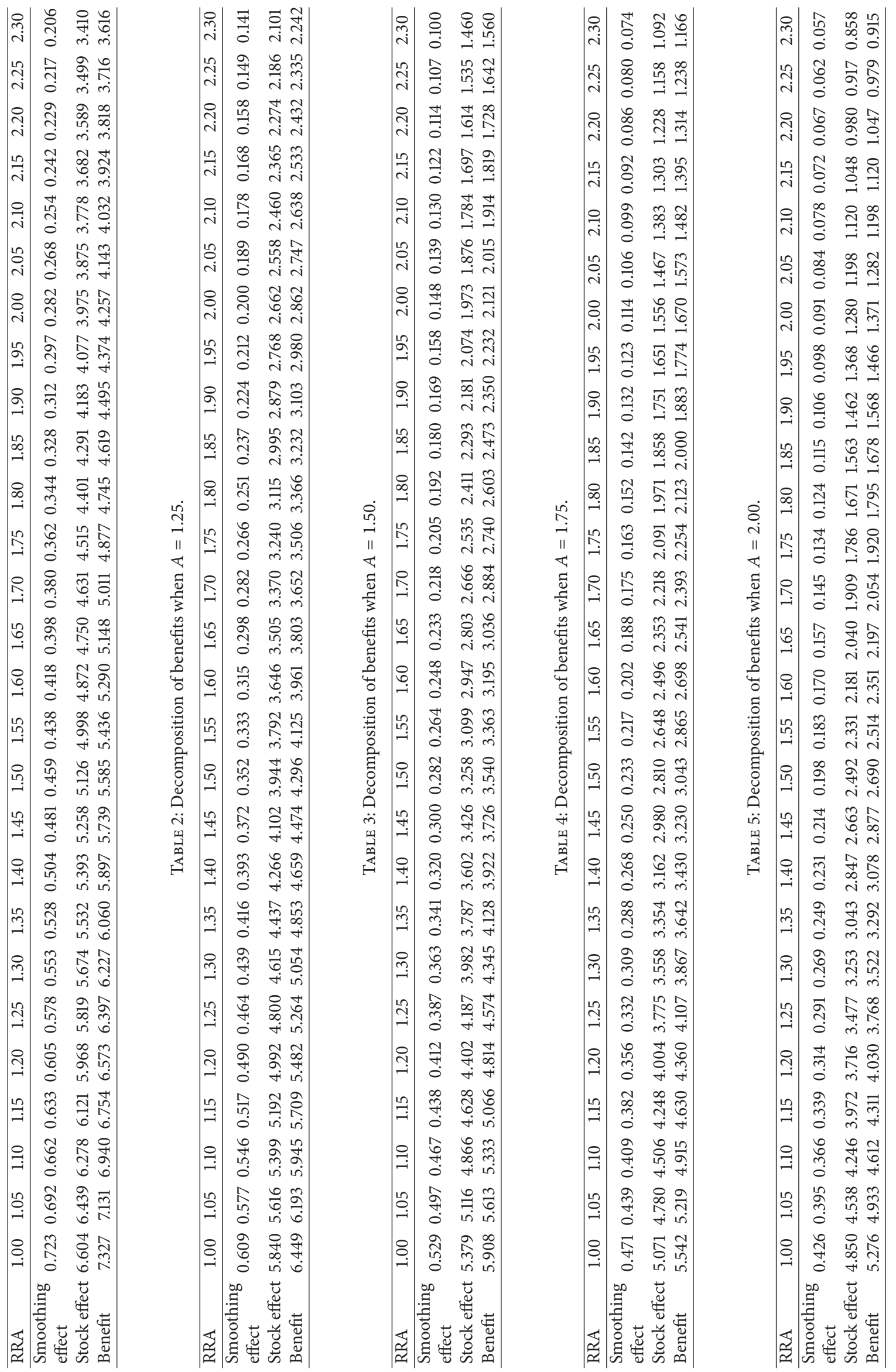




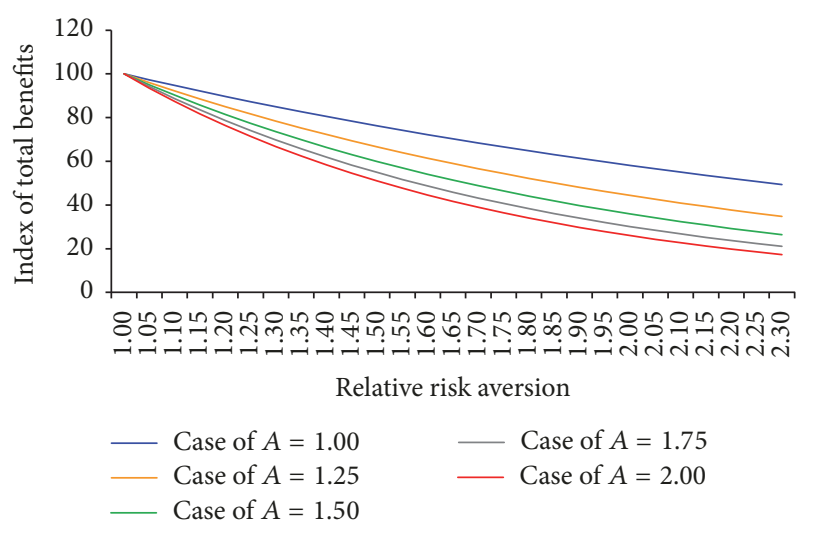

FIGURE 4: Relative risk aversion and index of total benefits.

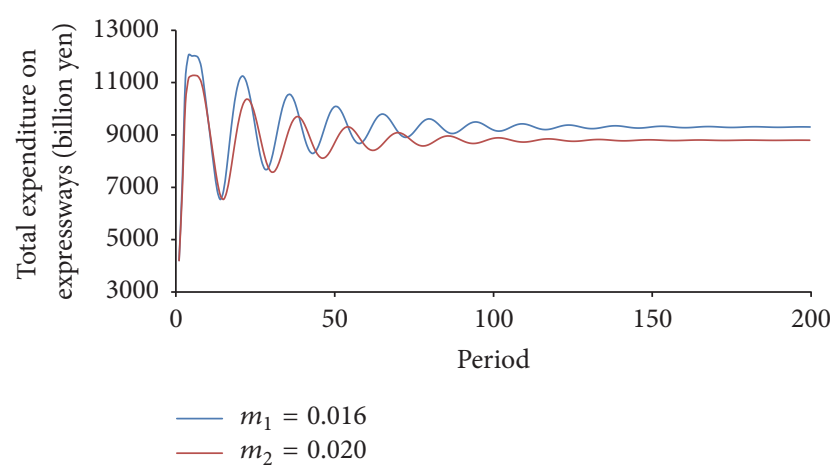

Figure 5: Dynamics of total expenditure on expressways.

to approach a steady state over time. Moreover, comparing the graphs in the cases of $m_{1}=0.016$ and $m_{2}=0.020$ in Figure 5, we note that the size of the fluctuation is small when the maintenance intensity is high.

Focusing on the transition process, it should be noted that total expenditure in the case where $m_{1}=0.016$ is larger than that in the case where $m_{2}=0.020$ in some periods. However, it is evident that total expenditure in the case where $m_{1}=0.016$ is larger than that in the case where $m_{2}=0.020$ in the steady state. When $m_{2}=0.020$ (i.e., the maintenance intensity is relatively high), the steady-state value of total expenditure on expressways is 8,799 billion Japanese yen. Conversely, when $m_{1}=0.016$ (i.e., the maintenance intensity is relatively low), the steady-state value of total expenditure on expressways is 9,303 billion Japanese yen. Therefore, in terms of total expenditure on expressways, which is defined as the sum of investment in replacement expressway stock and expenditure on expressway maintenance, the case where maintenance intensity is high will cost less than the case where maintenance intensity is low in the long term.

Figure 6 shows movements in user charges in the cases where $m_{1}=0.016$ and $m_{2}=0.020$. At first glance, we find that the behavior of user charges is very similar to that of total expenditure on expressways. As can be seen in Figure 6, user charges show cyclical fluctuations during the transition process in both cases. In the steady state, user charges in the

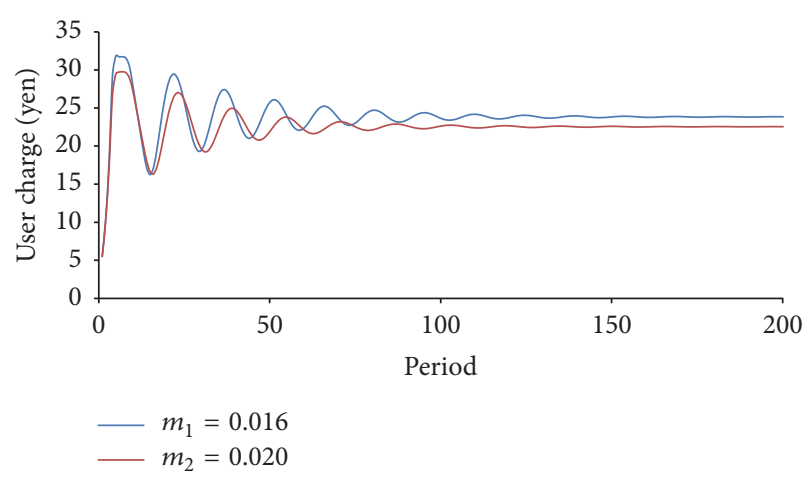

Figure 6: Dynamics of user charges.

case where $m_{2}=0.020$ are less than those in the case where $m_{1}=0.016$. That is, user charges are lower in the long term when maintenance intensity is relatively high.

Let $P^{*}$ be the steady-state value of user charges for an expressway. We can obtain the value of $P^{*}$ using the following equation:

$$
P^{*}=\frac{I^{g *}+M^{*}}{R \times G^{*} \times 365 \times 5^{\prime}},
$$

where $R$ is the average daily traffic volume for Japanese expressways. Data for $R$ are taken from [29], and the average daily volume of expressway traffic is 27,481 units. Using (47) for the case where $m_{2}=0.020$, the user charge per kilometer in the steady state is 22.54 Japanese yen. Similarly, the user charge per kilometer in the steady state in the case where $m_{1}=$ 0.016 is 23.83 Japanese yen.

4.2. Efficiency and Intergenerational Equity. To compare the short-term and long-term social marginal cost pricing systems of roads, [4] presented a quantitative approach for evaluating efficiency and intergenerational equity regarding road construction and improvement. Using the evaluation index described in [5], they define efficiency and intergenerational equity as follows. The sum of the benefits for all generations is regarded as an efficiency index. In addition, the inverse of the standard deviation of net benefits is regarded as an equity index. Here, the net benefits are derived as the residual after subtracting the burden from the benefits; that is, net benefits equal benefits minus the burden. Paper [4] examined six road-use charging systems: a short-term social marginal cost pricing system, a long-term social marginal cost pricing system, and four intermediate cases. As a result, they find that there is a trade-off between efficiency and intergenerational equity. In particular, the long-term social marginal cost pricing system is superior in terms of efficiency, while the short-term social marginal cost pricing system is superior in terms of intergenerational equity.

In this subsection, we apply the approach proposed by [4] to the numerical analysis of efficiency and intergenerational equity in the context of the model of life-extension investment in expressways. Specifically, we address the following questions: What kind of relationship exists between efficiency 
and intergenerational equity associated with life-extension investment in expressways? Are efficiency and intergenerational equity encouraged or deterred by technological advances?

However, unlike [4], we calculate efficiency and intergenerational equity using the benefits of life-extension investment in expressways $V\left(m_{2}, m_{1}\right)$ and total expenditure on expressways $\left(I_{t}^{g}+M_{t}\right)$, respectively. Recall that we analyzed management of investment and maintenance in relation to expressway infrastructure at a national level in the dynamic framework based on the model of economic growth. Because the results of the numerical analysis of [4] depend on an essentially static model, we have a distinct advantage over [4] from the perspective of the appropriateness of using generational accounting. In addition, [4] did not consider changes in RRA and the level of technology.

To apply the generational accounting technique, first we must convert the annual benefits and burden into those of a generation. Specifically, we define the present value of the difference between total expenditure on expressways when $m_{1}=0.016$ and that when $m_{2}=0.020$ as a burden per period. Furthermore, as in [4], we assume that all generations utilize the expressways over four decades from age 20 to age 59. Because we consider a period to be five years, this means that each generation uses the expressways over eight periods. The benefits (burden) for each generation are (is) the sum of 12.5 percent of the benefits (burden) in each period. Taking generation $t$, which is born in period $t$, as an example, the people of generation $t$ use the expressway for eight periods (over four decades) from period $t+4$ to period $t+11$. Then, we calculate the benefits of generation $t$ by

$$
\begin{aligned}
& 0.125 \times(\text { benefits in period } t+4)+0.125 \\
& \times(\text { benefits in period } t+5)+\cdots+0.125 \\
& \times(\text { benefits in period } t+11)
\end{aligned}
$$

See [4] for a more detailed explanation of (48).

We use the following nine values for the RRA parameter: $\sigma=1.00,1.50,2.00,2.50,3.00,3.50,4.00,4.50$, and 5.00. Figure 7 shows the relationship between efficiency and intergenerational equity in our model. As can be seen in Figure 7, there are downward sloping lines for all values of the technology parameter, implying a trade-off between efficiency and intergenerational equity. Here, the points in the top left corner of the graphs have $\sigma=1.00$, while those in the bottom right corner of the graph have $\sigma=5.00$. That is, RRA is lower for points located in the upper left corner of the graph. The main results are summarized as follows. If RRA increases, efficiency decreases and intergenerational equity increases. Given that [33] presents estimates of RRA in Japan and the United States of 2.76 and 1.19, respectively, Figure 7 suggests that people in Japan place a higher value on intergenerational equity than do people in the United States. Conversely people in the United States place a higher value on efficiency than do people in Japan. In addition, our interest is how technological progress would impact efficiency and intergenerational equity given a life-extension investment policy. A country with a higher level of technology can obtain

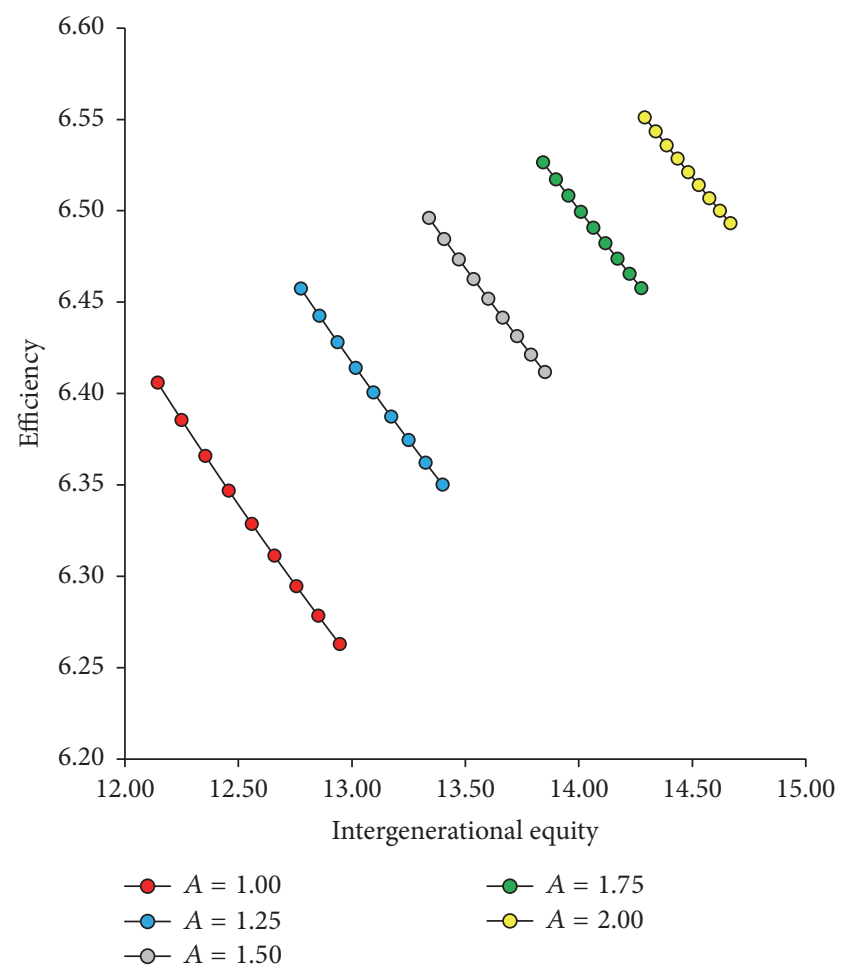

FIGURE 7: The relationship between efficiency and intergenerational equity.

both greater efficiency and greater intergenerational equity. This implies that technological progress plays a key role in improving both efficiency and intergenerational equity.

\section{Conclusion}

Based on the stochastic Ramsey model, we proposed a macroeconomic dynamics approach for evaluating lifeextension investment policies for expressways in Japan. The proposed approach allows more comprehensive and rigorous analysis.

We found that the benefits of life-extension investment in expressways are increased by raising the level of maintenance intensity. The benefits of life-extension investment in expressways can be decomposed into the stock effect and the smoothing effect. The numerical results showed that the stock effect accounts for more than 90 percent of the benefits, while the smoothing effect accounts for less than 10 percent. We also examined the effects of life-extension investment policies under varying levels of maintenance intensity and obtained the following results. A life-extension investment policy with a high level of maintenance intensity leads to lower total expenditure on expressways in the long term. In the short term, the magnitude of the fluctuations in expressway expenditure is smaller when there is a high level of maintenance intensity than when there is a low level of maintenance intensity. That is, increasing the level of maintenance intensity suppresses fluctuations in expressway expenditure and contributes to a reduction in financial instability in 
relation to expressway expenditure. Moreover, user charges are lower in the long term when maintenance intensity is relatively high. Our results support the life-extension policies regarding expressways of NEXCO and the Ministry of Land, Infrastructure, Transport and Tourism in Japan.

Regarding efficiency and intergenerational equity under a life-extension investment policy in relation to expressways, the socially optimal combination of efficiency and intergenerational equity depends on the levels of relative risk aversion and technological development. If relative risk aversion is high, efficiency will be low and intergenerational equity will be high. Moreover, a higher level of technological development leads to greater efficiency and intergenerational equity. This suggests that technological progress is important for increasing efficiency and intergenerational equity.

\section{Appendix}

\section{A. Proof That $Y^{*}, C^{*}, K^{*}, G^{*}, I^{k *}, I^{g *}$, and $g^{1 *}$ Are Constant in the Steady State}

Combining (10) and (11), (15) can be expressed as

$$
\begin{aligned}
\left(\frac{C_{t}}{\bar{L}}\right)^{-\sigma}= & \beta\left(\frac{C_{t+1}}{\bar{L}}\right)^{-\sigma} \alpha_{k} A G_{t+1}^{\alpha_{g}} K_{t+1}^{\alpha_{k}-1} \bar{L}^{1-\alpha_{k}} \\
& +\beta\left(\frac{C_{t+1}}{\bar{L}}\right)^{-\sigma}\left(1-\delta_{k}\right) .
\end{aligned}
$$

When both sides of (A.1) are divided by $\left(C_{t+1} / \bar{L}\right)^{-\sigma}$, we obtain

$$
\begin{aligned}
\left(\frac{C_{t+1}-C_{t}}{C_{t}}+1\right)^{\sigma}= & \beta \alpha_{k} A G_{t+1}^{\alpha_{g}} K_{t+1}^{\alpha_{k}-1} \bar{L}^{1-\alpha_{k}} \\
& +\beta\left(1-\delta_{k}\right) .
\end{aligned}
$$

In the steady state, all variables grow at constant nonnegative rates. Obviously, the consumption growth rate, $\left(C_{t+1}-C_{t}\right) / C_{t}$, in the steady state must be a constant. It follows that the lefthand side of (A.2) is a constant. Then, the right-hand side of (A.2) is also a constant. This implies the constancy of the term $G_{t+1}^{\alpha_{g}} K_{t+1}^{\alpha_{k}-1}$. In other words, the following relationship holds:

$$
\mu=G_{t+1}^{\alpha_{g}} K_{t+1}^{\alpha_{k}-1}
$$

where $\mu$ is a constant.

Note that if $s=2$, expressway stock is at the limit of serviceability. This means that the shadow value of expressway stock is zero: $\chi_{t+1}^{g, 2}=0$. Using (14), (16) can be rewritten as follows:

$$
\begin{aligned}
\chi_{t}^{g, 1}= & \beta \xi_{t+1}+\beta \chi_{t+1}^{g, 1}\left\{1-\phi_{1}(m)\right\}+\beta \chi_{t+1}^{g, 2} \phi_{1}(m) \\
= & \beta \lambda_{t+1}\left(\alpha_{g} A G_{t+1}^{\alpha_{g}-1} K_{t+1}^{\alpha_{k}} \bar{L}^{1-\alpha_{k}}-m\right) \\
& +\beta \chi_{t+1}^{g, 1}\left\{1-\phi_{1}(m)\right\} .
\end{aligned}
$$

Therefore, the relationships (A.4), (10), and (12) imply that

$$
\begin{aligned}
\left(\frac{C_{t}}{\bar{L}}\right)^{-\sigma}= & \beta\left(\frac{C_{t+1}}{\bar{L}}\right)^{-\sigma}\left(\alpha_{g} A G_{t+1}^{\alpha_{g}-1} K_{t+1}^{\alpha_{k}} \bar{L}^{1-\alpha_{k}}-m\right) \\
& +\beta\left(\frac{C_{t+1}}{\bar{L}}\right)^{-\sigma}\left\{1-\phi_{1}(m)\right\} .
\end{aligned}
$$

Dividing both sides of (A.5) by $\left(C_{t+1} / \bar{L}\right)^{-\sigma}$ yields

$$
\begin{aligned}
\left(\frac{C_{t+1}-C_{t}}{C_{t}}+1\right)^{\sigma}= & \beta\left(\alpha_{g} A G_{t+1}^{\alpha_{g}-1} K_{t+1}^{\alpha_{k}} \bar{L}^{1-\alpha_{k}}-m\right) \\
& +\beta\left\{1-\phi_{1}(m)\right\} .
\end{aligned}
$$

Because the growth rate of consumption becomes constant in the steady state, the left-hand side of (A.6) is a constant. Then, the right-hand side of (A.6) is also a constant and the following relationship must hold:

$$
v=G_{t+1}^{\alpha_{g}-1} K_{t+1}^{\alpha_{k}}
$$

where $v$ is a constant.

Combining (A.3) and (A.7), the relationship between $K_{t+1}$ and $G_{t+1}$ can be expressed as

$$
K_{t+1}=\left(\frac{\nu}{\mu}\right) G_{t+1} .
$$

Substitution of (A.8) into (A.2) leads to

$$
\begin{aligned}
\left(\frac{C_{t+1}-C_{t}}{C_{t}}+1\right)^{\sigma}= & \beta \alpha_{k} A G_{t+1}^{\alpha_{g}} K_{t+1}^{\alpha_{k}-1} \bar{L}^{1-\alpha_{k}} \\
& +\beta\left(1-\delta_{k}\right) \\
= & \beta \alpha_{k} A\left(\frac{\nu}{\mu}\right)^{\alpha_{k}-1} G_{t+1}^{\alpha_{k}+\alpha_{g}-1} \bar{L}^{1-\alpha_{k}} \\
& +\beta\left(1-\delta_{k}\right) .
\end{aligned}
$$

Because the left-hand side of (A.9) is a constant, the righthand side of (A.9) is also a constant. Consequently, we find that expressway stock in the steady state is a constant and the relationship $G_{t}=G_{t+1}=G^{*}$ holds. In addition, (A.2) and (A.8) imply that

$$
\begin{aligned}
\left(\frac{C_{t+1}-C_{t}}{C_{t}}+1\right)^{\sigma}= & \beta \alpha_{k} A\left(\frac{\mu}{\nu}\right)^{\alpha_{g}} K_{t+1}^{\alpha_{g}+\alpha_{k}-1} \bar{L}^{1-\alpha_{k}} \\
& +\beta\left(1-\delta_{k}\right) .
\end{aligned}
$$

From (A.10), we can show that capital stock other than expressways is constant in the steady state and the relationship $K_{t}=K_{t+1}=K^{*}$ holds.

When $K_{t}=K_{t+1}=K^{*}$, (3) implies that $I_{t}^{k *}=\delta_{k} K^{*}$ in the steady state. Therefore, investment other than that in expressways, $I^{k *}$, is a constant. Moreover, if $G_{t}=G_{t+1}=G^{*}$, then $m G^{*}=M^{*}$. Hence, expenditure on expressway maintenance in the steady state becomes a constant. In addition, we find from (4) that the relationship $G^{*}=g^{1 *}$ holds and 
expressway stock with deterioration vintage 1 becomes constant in the steady state. Furthermore, it follows from (6) that investment in expressways, $I^{g *}$, is constant.

We now focus on the production function of (1). Because $G^{*}$ and $K^{*}$ become constant in the steady state, the production of goods, $Y^{*}$, must be constant. Moreover, (3) can be rewritten as follows:

$$
C^{*}=Y^{*}-I^{k *}-I^{g *}-M^{*}
$$

The right-hand side of (A.11) is a constant in the steady state. This implies that consumption in the steady state is also a constant.

Hence, the proposition that $Y^{*}, C^{*}, K^{*}, G^{*}, I^{k *}, I^{g *}$, and $g^{1 *}$ become constant in the steady state is proved.

\section{B. Derivation of (18) and (19)}

In Appendix A, we confirm that the relationships $K_{t}=K_{t+1}=$ $K^{*}, G_{t}=G_{t+1}=G^{*}$, and $C_{t}=C_{t+1}=C^{*}$ hold in the steady state. Then, (A.2) and (A.6) imply that

$$
\begin{aligned}
& 1=\beta \alpha_{k} A G^{* \alpha_{g}} K^{* \alpha_{k}-1} \bar{L}^{1-\alpha_{k}}+\beta\left(1-\delta_{k}\right), \\
& 1=\beta\left(\alpha_{g} A G^{* \alpha_{g}-1} K^{* \alpha_{k}} \bar{L}^{1-\alpha_{k}}-m\right)+\beta\left\{1-\phi_{1}(m)\right\} .
\end{aligned}
$$

Note that (B.1) and (B.2) are identical to (18) and (19), respectively.

We now express $\chi^{k *}, \chi^{g, 1 *}$, and $\lambda^{*}$ as the values in the steady state of $\chi_{t}^{k}, \chi_{t}^{g, 1}$, and $\lambda_{t}$, respectively. From (15) and (B.1), $\chi^{k *}=1$ holds. Considering the relationship between (16) and (B.2), we get $\chi^{g, 1 *}=1$. Hence, (11) and (12) imply that $\lambda^{*}=1$.

\section{Conflicts of Interest}

The authors declare that there are no conflicts of interest regarding the publication of this paper.

\section{Acknowledgments}

This work is supported in part by a Grant-in-Aid for Scientific Research (C) (15K03461) from the Japan Society for the Promotion of Science.

\section{References}

[1] D. David, "The Japanese experience with highway development," Journal of Infrastructure Development, vol. 6, no. 1, pp. 17-42, 2014.

[2] N. Akai and T. Takemoto, "Future renewal costs for road infrastructure and financial burden on each prefecture: estimates on roads managed by prefectures," Financial Review, vol. 124, pp. 113-140, 2015 (Japanese).

[3] S. Segi and K. Kobayashi, "Dynamic infrastructure investment strategies and life-extension benefits," Journal of Japan Society of Civil Engineers, Series D3, vol. 70, no. 3, pp. 179-197, 2014 (Japanese).
[4] Y. Misui and T. Nemoto, "Road planning through long-run marginal social cost pricing," The Japanese Journal of Transportation Economics, vol. 54, pp. 275-284, 2011 (Japanese).

[5] L. J. Kotlikoff, Generational Accounting: Knowing Who Pays, and When, for What We Spend, Free Press, 1992.

[6] K. J. Arrow and M. Kurz, Public Investment, the Rate of Return, and Optimal Fiscal Policy, Johns Hopkins Press, 1970.

[7] R. J. Barro, "Government spending in a simple model of endogeneous growth," Journal of Political Economy, vol. 98, no. 5, Part 2, pp. S103-S125, 1990.

[8] S. J. Turnovsky, "Fiscal policy, adjustment costs, and endogenous growth," Oxford Economic Papers, vol. 48, no. 3, pp. 361381, 1996.

[9] N. Hashimzade and G. D. Myles, "Growth and public infrastructure," Macroeconomic Dynamics, vol. 14, no. S2, pp. 258-274, 2010.

[10] K. Futagami, Y. Morita, and A. Shibata, "Dynamic analysis of an endogenous growth model with public capital," The Scandinavian Journal of Economics, vol. 95, no. 4, pp. 607-625, 1993.

[11] S. J. Turnovsky, "Fiscal policy in a growing economy with public capital," Macroeconomic Dynamics, vol. 1, no. 3, pp. 615-639, 1997.

[12] R. A. Escobar-Posada and G. Monteiro, "Long-run growth and welfare in a two sector endogenous growth model with productive and non-productive government expenditure," Journal of Macroeconomics, vol. 46, pp. 218-234, 2015.

[13] S. Ghosh and U. Roy, "Optimal growth with public capital and public services," Economics of Planning, vol. 35, no. 3, pp. 271292, 2002.

[14] S. Ghosh and U. Roy, "Fiscal policy, long-run growth, and welfare in a stock-flow model of public goods," Canadian Journal of Economics, vol. 37, no. 3, pp. 742-756, 2004.

[15] C. Tsoukis and N. J. Miller, "Public services and endogenous growth," Journal of Policy Modeling, vol. 25, no. 3, pp. 297-307, 2003.

[16] F. K. Rioja, "Filling potholes: Macroeconomic effects of maintenance versus new investments in public infrastructure," Journal of Public Economics, vol. 87, no. 9-10, pp. 2281-2304, 2003.

[17] P. Kalaitzidakis and S. Kalyvitis, "On the macroeconomic implications of maintenance in public capital," Journal of Public Economics, vol. 88, no. 3-4, pp. 695-712, 2004.

[18] E. V. Dioikitopoulos and S. Kalyvitis, "Public capital maintenance and congestion: long-run growth and fiscal policies," Journal of Economic Dynamics \& Control, vol. 32, no. 12, pp. 3760-3779, 2008.

[19] P.-R. Agénor, "Infrastructure investment and maintenance expenditure: optimal allocation rules in a growing economy," Journal of Public Economic Theory, vol. 11, no. 2, pp. 233-250, 2009.

[20] Ministry of Land, Infrastructure, Transport, and Tourism, "Road statistics annual report 2016," 2016 (in Japanese), http:// www.mlit.go.jp/road/ir/ir-data/tokei-nen/.

[21] T. Tokunaga, "Renewal plan for the metropolitan expressway," Concrete Journal, vol. 54, no. 1, pp. 9-14, 2016.

[22] T. Matsuzaka, Y. MoriyamA, K. Ozasa et al., "Study for longterm plan of structural replacement and rehabilitation on expressways in Japan," Journal of Japan Society of Civil Engineers, Series F4, vol. 73, no. 1, pp. 1-18, 2017 (Japanese).

[23] K. Izumi and Y. Fujino, "Integrated management of maintenance in the metropolitan expressway network," Doboku Gakkai Ronbunshuu F, vol. 65, no. 3, pp. 326-345, 2009 (Japanese). 
[24] K. Otsu, "The current situation and maintenance of expressways in Japan," in Proceedings of the 3rd International Conference on Sustainable Construction Materials and Technologies, 2013.

[25] S. Takada, T. Mizutani, and Y. Fujino, "Analysis on maintenance cost and case studies of urban expressways in Japan and USA," Journal of Structural Engineering A, vol. 61A, pp. 513-521, 2015 (Japanese).

[26] "Technical Committee of the Method of the Long-term Maintenance of Expressway Assets," Final report of the method of the long-term maintenance of expressway assets, 2014, http://www.e-nexco.co.jp/pressroom/committee/pdfs/140122/ 04.pdf.

[27] E. Shioji, "Public capital and economic growth: a convergence approach," Journal of Economic Growth, vol. 6, no. 3, pp. 205$227,2001$.

[28] S. Segi, Study on the dynamic investment policy considering deterioration process of public capital [Ph.D. dissertation], Kyoto University, 2014, (in Japanese).

[29] Ministry of Land, Infrastructure, Transport, and Tourism, "Road traffic census 2010," 2008 (in Japanese), http://www.mlit .go.jp/road/census/h22-1/index.html.

[30] Cabinet Office, "Preliminary quarterly estimates of gross capital stock of private enterprises," 2015 (in Japanese), http://www.esri .cao.go.jp/jp/sna/data/data_list/minkan/files/files_minkan.html.

[31] Ministry of Land, Infrastructure, Transport, and Tourism, "Road statistics annual report 2015," 2015 (in Japanese), http:// www.mlit.go.jp/road/ir/ir-data/tokei-nen/index.html.

[32] Cabinet Office, Social Capital of Japan: A Stock Transcending Generations, National Printing Bureau, 2002, (in Japanese).

[33] G. G. Szpiro, "Relative risk aversion around the world," Economics Letters, vol. 20, no. 1, pp. 19-21, 1986.

[34] K. Shimono, "Estimating the magnitude of risk aversion," Oikonomika, vol. 37, no. 1, pp. 1-14, 2000 (Japanese). 


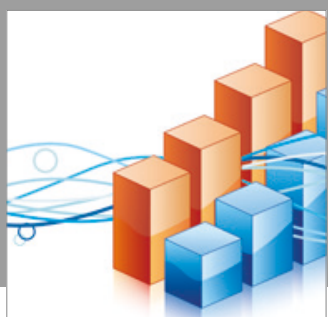

Advances in

Operations Research

vatersals

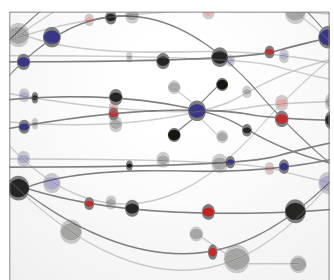

\section{The Scientific} World Journal
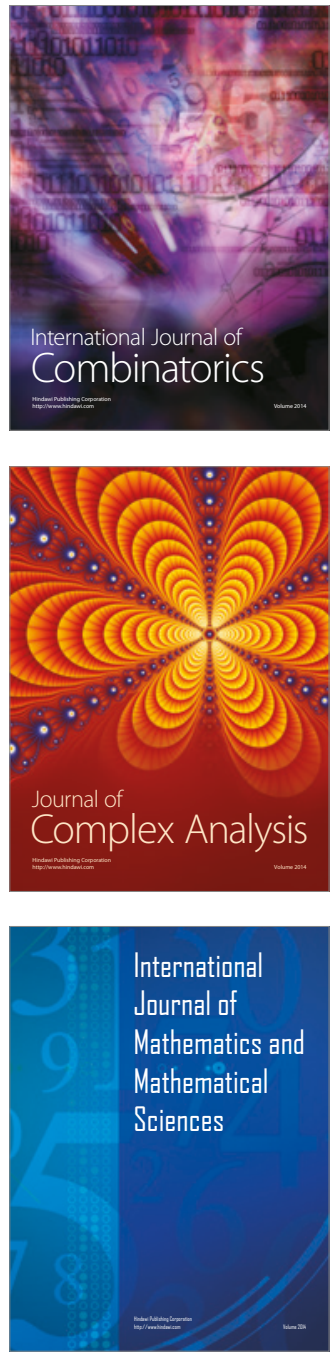
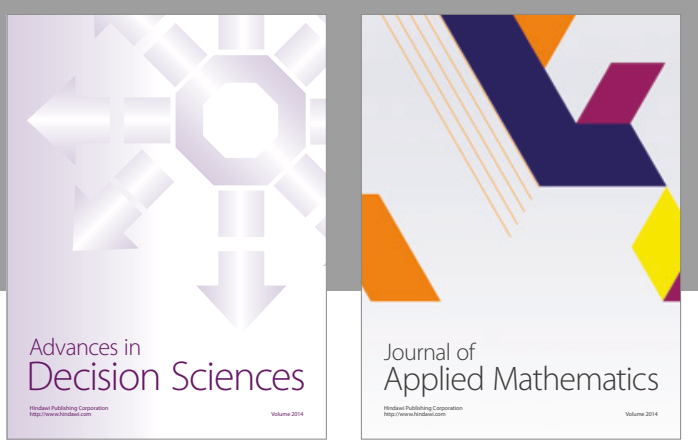

Algebra

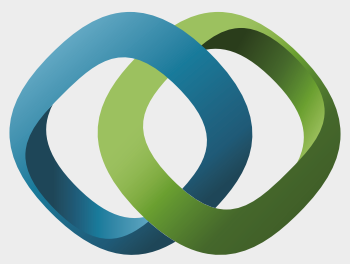

\section{Hindawi}

Submit your manuscripts at

https://www.hindawi.com
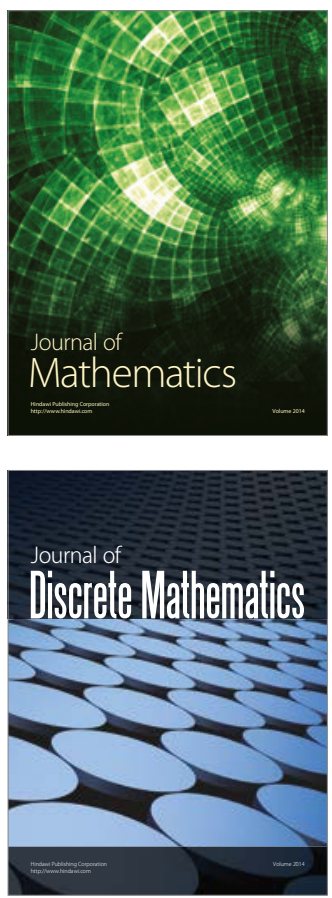

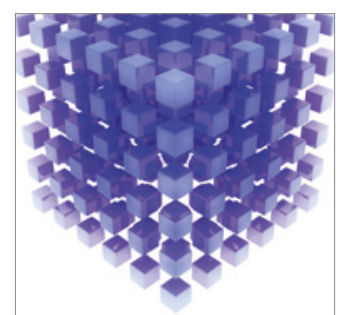

Mathematical Problems in Engineering
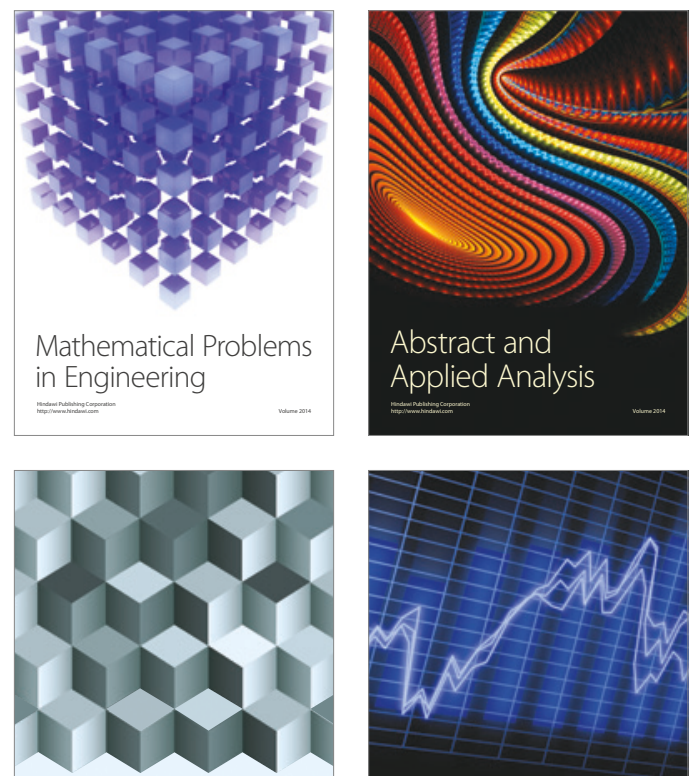

Journal of

Function Spaces

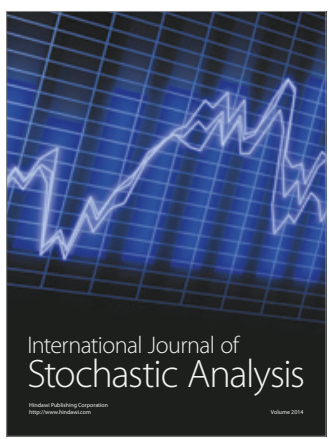

Probability and Statistics
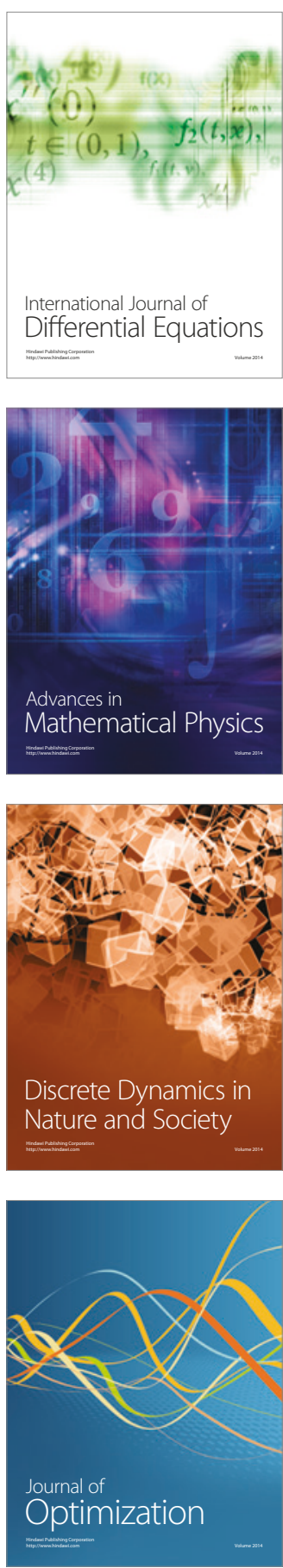